\title{
Synthesis, Characterization and Ultra filtration of Reactive Dyes. Application by Exhaustion and/or Ink-Jet Printing. III
}

\author{
${ }^{1 * \text { Smaro Lykidou, }}{ }^{2}$ Evangelos Karanikas, ${ }^{3}$ Nikolaos Nikolaidis, ${ }^{4}$ Eforia Tsatsaroni \\ Department of Industrial Chemistry and Chemical Technology, School of Chemistry, Aristotle \\ University of Thessaloniki, Thessaloniki, Greece \\ I*slykidou@chem.auth.gr, ${ }^{2}$ vagkaran@gmail.com, ${ }^{3}$ nikosnikolaidis@kykehellas.gr, \\ ${ }^{4}$ tsatsaro@chem.auth.gr
}

\begin{abstract}
Three new azo reactive dyes of different metallic salts $(\mathrm{Na}, \mathrm{K}, \mathrm{Li})$ were synthesized. The dyes were purified-concentrated by ultrafiltration technology, characterized and applied on cotton, wool and nylon 66 fabric by exhaustion (dyeing) and by ink-jet printing. Fastness properties of the dyeings were measured. Wash fastness was found to be very good to excellent in all cases, while light fastness values were medium to low. Ink-jet ink formulations were prepared using the ultrafiltrated dyes UF RR(a-c) and their properties $p H$, conductivity, surface tension and viscosity were monitored over a period of 90 days. The inks were used to print digitally cotton and nylon 66 samples and wash-and light fastness properties of the prints were measured. Wash fastness properties were excellent while light fastness values are low Colour measurements of the dyeings and prints were conducted.
\end{abstract}

Keywords: reactive dyes, polyamide membrane, ultrafiltration, ink-jet printing

Abbreviations: UF (ultrafiltration), CC (colour change), CS (colour staining), diac (diacetate), $c=($ cotton), $p a=($ polyamide $)$, pes $=($ polyester $), w=($ wool $)$, omf $($ on mass

fibre)

\section{INTRODUCTION}

Reactive dyes are dyes capable of reacting chemically with a substrate to form a covalent dye substrate linkage. This covalent bond is formed between the dye molecule and the terminal $-\mathrm{OH}$ (hydroxyl) group of cellulosic fibres and the terminal $-\mathrm{NH}_{2}$ (amino) group of polyamide of wool fibres $[1,2]$. Due to the covalent bond formed between the dye molecule and the reactive group of the fibre reactive dyes have good fastness properties and are commonly used in dyeing those fibres mainly cellulosic fibres like cotton [1-3].

In continuation of previous work on the synthesis of azo dyes and their purification by using membrane technology (ultrafiltration) [4-6] three new azo reactive dyes of different metallic salt (Na, $\mathrm{K}$, Li) were synthesized in this work. The dyes were purified-concentrated by ultrafiltration technology, characterized and applied on cotton, wool and nylon 66 fabric by exhaustion (dyeing) and ink-jet printing.

Ultrafiltration is a modern ecological separation method acting as molecular separation method avoiding the use of chemicals and applied mainly for the treatment of textile effluents [7-11]. The use of ultra-filtration technology in dye synthesis represents a new application area of ultrafiltration which allows the production of highly purified dyes with the elimination of inorganic salts either present in the raw materials or added during the synthesis process and also low molecular weight by-products produced during the synthesis process $[10,11]$. The ultrafiltrated purified dyes have higher coloristic yield, brighter shades and higher solubility, thus allowing the production of high quality and high strength liquid formulations suitable for digital inkjet applications.

The present paper describes the synthesis of novel and simple reactive dyes in different salt formation. The dyes synthesized were characterized by their spectrophotometrical data UV-Vis and FT-IR and their elemental analysis. Optical Emission Spectroscopy was performed in the UF-permeate for the determination of the membrane eliminated inorganic salts present in the synthesized dyes. The use of different salts aims in the production of highly soluble dyes which with the use of ultrafiltration 
technology will further purify and increase colororistic yield of the resulting novel reactive dyes. The production of high solubility, purity and coloristic strength reactive dyes would allow the production of intense digital ink printed colours otherwise unachievable with common reactive digital printing inks

Water based inks were prepared with the novel ultrafiltrated reactive dyes of the various salts synthesized and their physicochemical properties $\mathrm{pH}$, conductivity, surface tension and viscosity were studied [12-14]. The inks were used for the digital inkjet printing of cotton, wool and nylon 66 samples. Colorimetric coordinates of the dyeings and prints are also performed.

\section{Materials}

Commercially available lightweight $\left(140 \mathrm{~g} / \mathrm{m}^{2}\right)$ bleached knitted cotton, wool and nylon 66 fabric was kindly supplied by KYKE Hellas (Greece) and was used throughout this work. The raw materials used for the synthesis of the dyes 1-amino-8-hydroxynaphthalene-3,6-disulfonic acid and 4-amino-2,5 di methoxy phenylene-beta hydroxyl ethyl sulphone sulfate ester were provided by MEGHMALI DYES AND INTERMEDIATES LTD (India).

The digital printing auxiliaries for cotton pretreatment, Infapret 7010 (an acrylic based agent used as an antimigrating agent), Anoxid RS/ (antireducing agent), were supplied by Prochimica (Italy).

\section{METHODS AND INSTRUMENTATION}

\subsection{Synthesis of Reactive Dyes I(a-c)}

A Shimadzu UV-2101 Spectrophotometer (Shimadzu Europe GmbH, Germany) was used for obtaining the absorption spectra. Melting points were determined using Differential Scanning Colorimeter Pyris 6 DSC (Perkin Elmer) holding $1.0 \mathrm{~min}$ in $30^{\circ} \mathrm{C}$, heating to $280{ }^{\circ} \mathrm{C}$, heating rate $20^{\circ} \mathrm{C} / \mathrm{min}$. Fourier Transform Infra-Red (FT-IR) spectra of the dye were recorded by FT-IR spectroscopy (FT-IR Spectrum One, PerkinElmer, USA resolution $4 \mathrm{~cm}^{-1}, 32$ scans, $4000-600 \mathrm{~cm}^{-1}$ ).

\section{Diazotization}

$17.05 \mathrm{~g}$ (0.05 moles) 4-amino-2,5 di methoxy phenylene-beta hydroxyl ethyl sulphone sulfate ester $\left(\mathrm{C}_{10} \mathrm{H}_{15} \mathrm{NO}_{8} \mathrm{~S}_{2} \mathrm{MW}=341\right.$ purity $\left.94.50 \%\right)$ were dissolved in $40 \mathrm{~mL}$ water at $5-10{ }^{\circ} \mathrm{C}$, under stirring for $2 \mathrm{~h}$. The mixture was acidified with $5.3 \mathrm{~mL}$ hydrochloric acid $10 \mathrm{~N}$. Ice was added to reach temperature $8-10{ }^{\circ} \mathrm{C}$. $6.9 \mathrm{~mL}$ sodium nitrite $\left(\mathrm{NaNO}_{2} 50 \%\right.$ in a water $)\left(8.5 \mathrm{~mL} \mathrm{KNO}_{2} 50 \%\right.$ in a water for the synthesis of potassium salt) was added dropwise under stirring (1h) keeping reaction temperature $<12^{\circ} \mathrm{C}$. After the nitrite solution was added, the reaction mass was stirred for $1 \mathrm{~h}$ to complete the reaction. Then the excess of sodium nitrite was destroyed by adding sulphamic acid in the reaction mass.

\section{Coupling}

$15.96 \mathrm{~g}$ (0.05 mole) of monoazoic salt of the $\mathrm{H}$-acid, 1-amino-8-hydroxynaphthalene-3,6-disulphonic acid $\left(\mathrm{C}_{10} \mathrm{H}_{10} \mathrm{NO}_{8} \mathrm{~S}_{2} \mathrm{MW}=359.31\right)$ was added in approx 60 min maintaining the temperature at $8-12{ }^{\circ} \mathrm{C}$. Sodium bicarbonate $\left(\mathrm{NaHCO}_{3}\right)\left(\mathrm{KHCO}_{3}\right.$ for the synthesis of potassium salt , $\mathrm{Li}_{2} \mathrm{CO}_{3}$ for the synthesis of lithium salt was added to reach a $\mathrm{pH}$ of 4.5-5.0 the addition takes approximately $2 \mathrm{~h}$ under stirring. Stirring continues for another $2 \mathrm{~h}$ the $\mathrm{pH}$ maintaining at 4-4.5 adding if necessary sodium bicarbonate When the $\mathrm{pH}$ was stable at 4.5-5 the disappearance of the azo component was verified by TLC (mobile phase: iso-butanol/n-Propanol/Ethylacetate/ $\mathrm{H}_{2} \mathrm{O} 20 / 40 / 10 / 30$ ). At this stage the reaction mass is soluble. After drying at $102{ }^{\circ} \mathrm{C} 37.13 \mathrm{~g}$ crude reactive red dye of no colour index (there is no colour index citation for this synthesized dye) was obtained (38.96 $\mathrm{g}$ as potassium salt and 33. $\mathrm{g}$ as mixed lithium/sodium salt). In the case of sodium and potassium reactive dye salts both reduction agent and neutralization agent was of the same salt thus resulting in the formation of a single salt either sodium or potassium whereas in the case of lithium a mixed reactive dye salt of sodium (from reduction) and lithium (from neutralization) was resulted (Figure 1). 

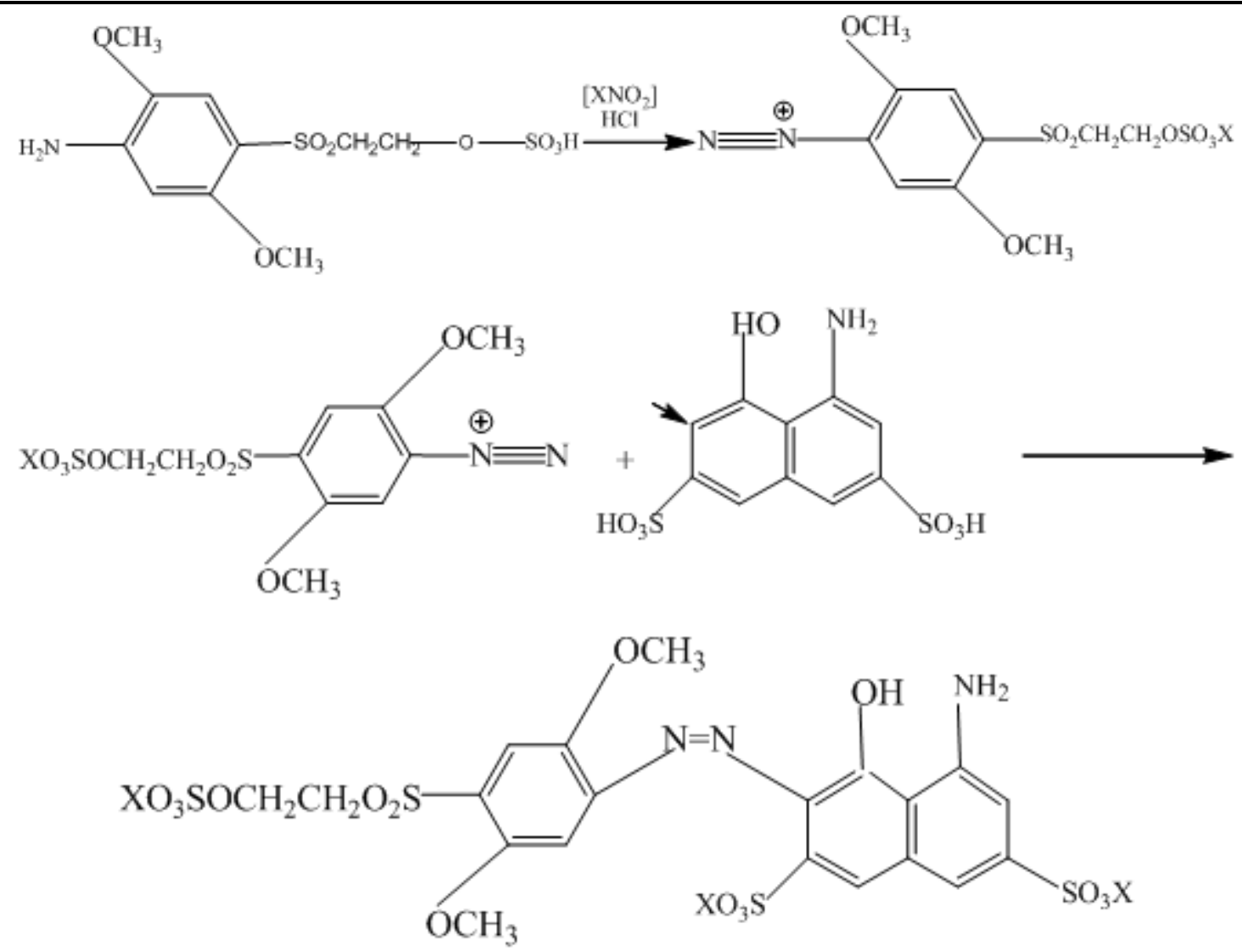

$\mathrm{a}: \mathrm{X}=\mathrm{Na}, \mathrm{b}: \mathrm{X}=\mathrm{K}, \mathrm{c}: \mathrm{X}=\mathrm{Li}$

Figure1. Synthesis of dyes $R R(a-c)$

The dyes synthesized were characterized by their spectrophotometrical data UV-Vis, FT-IR and elemental analyses. Atomic absorption measurements in the UF-permeate were also performed.

\subsection{Ultrafiltration}

A laboratory ultrafiltration unit equipped with tubular membrane supplied by PCI Membranes (UK) was used throughout this work. The membrane used for the ultrafiltration process was the polyamide type AFC 40 [15]. Aqueous dye solutions at $0.5 \% \mathrm{w} / \mathrm{v}$ for synthesized dyes RR(a-c) were prepared. An initial volume of $3 \mathrm{~L}$ of the dye solution was passed through the ultrafiltration unit at constant temperature of $40-50{ }^{\circ} \mathrm{C}$. $6 \mathrm{~L}$ of water at $40-50{ }^{\circ} \mathrm{C}$ was added into the unit to maintain initial volume of $3 \mathrm{~L}$ constant keeping diafiltration rate at $1: 2$ volume. The flow rate was $40-70 \mathrm{~L} / \mathrm{h} / \mathrm{m}^{2}$ and the unit was operating at 18 bar pressure constant for the whole duration. After the completion of diafiltration a concentration step was performed reducing the dye volume from $3 \mathrm{~L}$ to $1.5 \mathrm{~L}$ [15].

\subsection{Solubility Test}

The appropriate amount of synthesized reactive dye before and after ultrafiltration was dissolved under stirring in distilled water in $200 \mathrm{~mL}$ to give the desired concentration. The temperature was brought to $95{ }^{\circ} \mathrm{C}$ within $5 \mathrm{~min}$ and kept at this temperature for $5 \mathrm{~min}$. The solution was then placed in a thermostatically controlled water bath at $25{ }^{\circ} \mathrm{C}$ where was kept under stirring for 2 hours. The solution was then filtered at $25^{\circ} \mathrm{C}$ under vacuum. The aspect of the filtered was examined in terms of insolubles and sediment left. The procedure was repeated for many concentrations of the dyes to find the maximum level of solubility of the dyes $[15,16]$.

\subsection{Quantitative Determination of $\mathrm{K}+\mathrm{Na}+\mathrm{SO} \overline{4}$ and $\mathrm{Cl}$ - ions}

The $\mathrm{K}^{+}, \mathrm{Na}^{+}$ions were measured using a Prodigy 7 ICP-OES (Inductively Coupled Plasma with Optical Emission Spectroscopy) by Teledyne Leeman.

The $\mathbf{S O}_{4}^{-}$ions were determined using a $\mathrm{HACH}$ DR 3900 Spectrophotometer. The $\mathrm{Cl}^{-}$ions were determined by standard titration with silver nitrate. 


\subsection{Dyeing}

Dyeings were performed in a Zeltex Vistacolor dyeing machine (Zeltex Inc., USA) with $2 \mathrm{~g}$ fabric and depth of dyeing $3 \%$ omf in a liquor ratio 1:20. In figures $2 \mathrm{a}$ and $2 \mathrm{~b}$ the dyeing process for the cotton (Fig.2a) and wool-nylon 66 (Fig. 2b) fabrics respectively is presented

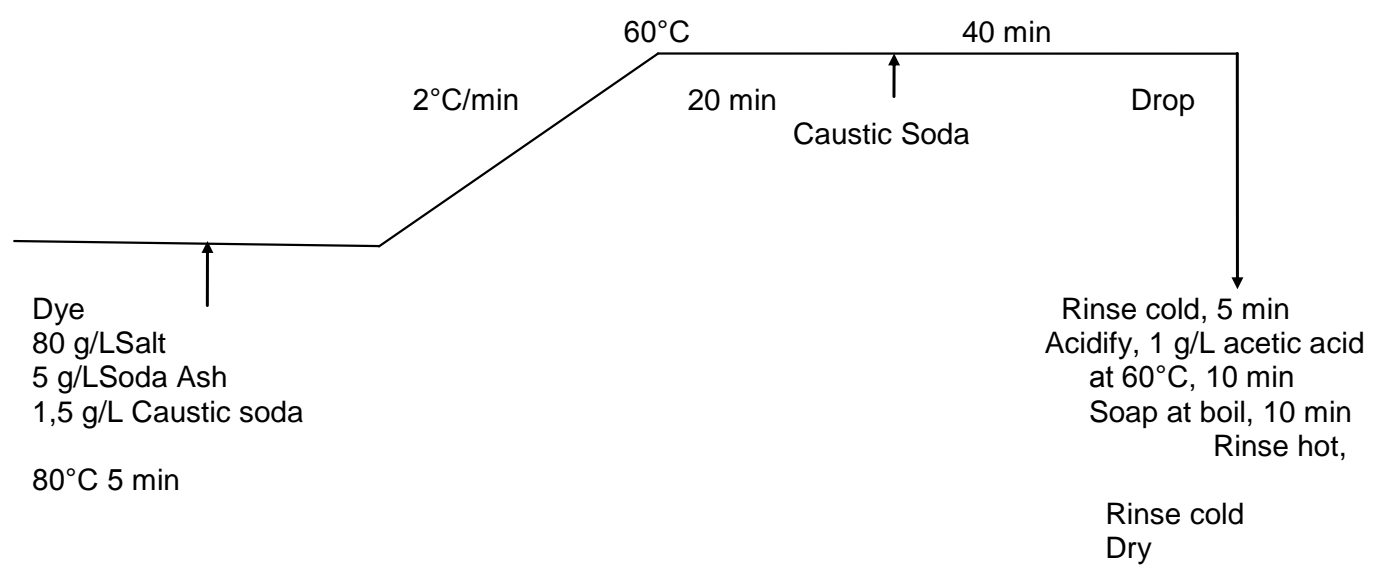

Figure2a. Cotton dyeing process

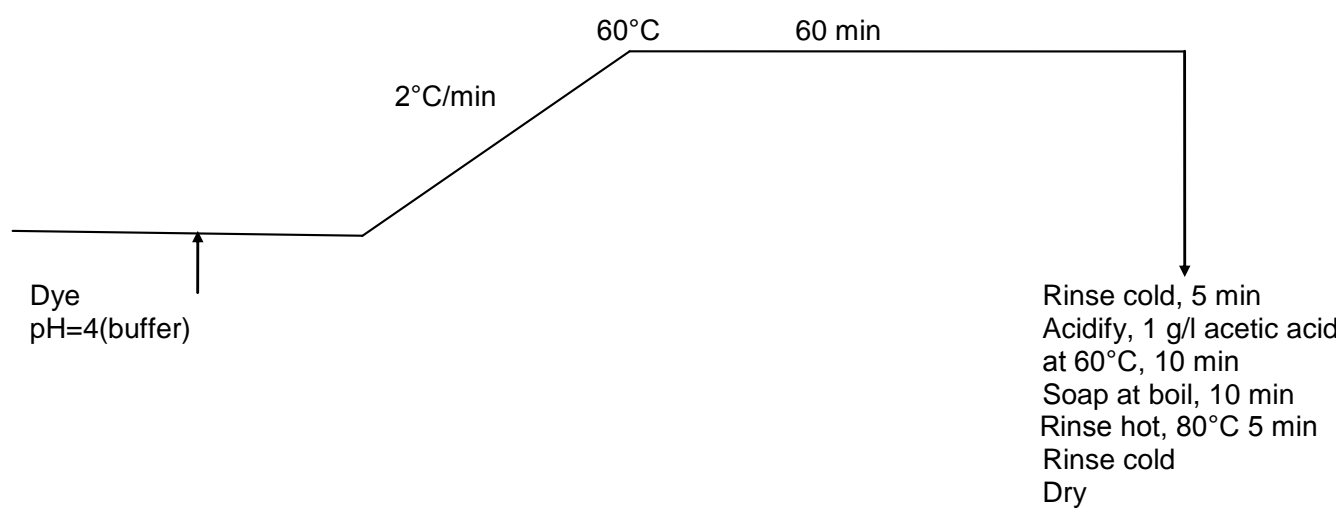

Figure2b. Wool and nylon 66 Dyeing Process

\subsection{Fastness Properties}

Wash fastness tests were carried out according to BS 10061990 CO6.

Light fastness was determined according to BS 10061990 BO2 using a Q-SUN Xe-1-B xenon light fastness machine.

Colour changes for all samples were assessed visually using a VeriVide D65 (UK) light cabinet [17].

\subsection{Colour Measurement}

Colour measurements were performed using a Macbeth CE 3000 spectrophotometer under D65 illumination, $10^{\circ}$ standard observer with UV included and specular component included. The samples were folded twice and four measurements were performed each time [18].

The K/S values were measured at the wavelength of maximum absorption using the equation 1 :

$$
K / S=\frac{(1-R)^{2}}{2 R}
$$

Where: $\mathrm{K}=$ absorbance coefficient

$\mathrm{S}=$ scattering coefficient

$\mathrm{R}=\%$ reflectance

\subsection{Inkjet Printing}

\subsubsection{Ink Formulation}

The water based ink formulations containing $1 \% \mathrm{w} / \mathrm{v}$ dye, $80 \% \mathrm{v} / \mathrm{v}_{2} \mathrm{O}$ and $20 \%$ butoxy ethanol as the water miscible organic solvent necessary in the inkjet emulsion were prepared by using a Sonicator UP100H (Hilscher, USA) homogenizer at room temperature for $10 \mathrm{~min}$. 
Synthesis, Characterization and Ultra filtration of Reactive Dyes. Application by Exhaustion and/or InkJet Printing. III

\subsubsection{Pretreatment of Samples and Digital Printing Process}

The samples were padded (80\% pick up) in a solution containing $150 \mathrm{~g} / \mathrm{L}$ Infapret 7010 (acting as an antimigrating agent), $30 \mathrm{~g} / \mathrm{L}$ sodium carbonate, $100 \mathrm{~g} / \mathrm{L}$ urea, and $20 \mathrm{~g} / \mathrm{L}$ Anoxid RS/T (as antireducing agent). The samples were then dried at $120{ }^{\circ} \mathrm{C}$, and left to cool down to room temperature for $10 \mathrm{~min}$. The samples pretreated as above were then digitally printed using the inkjet inks prepared as above.

\subsubsection{Surface Tension, Conductivity, Viscosity and pH Measurements of the Ink Formulations}

Surface tension measurements were made using a KSV Sigma 70 tensiometer (KSV Instruments, Helsinki, Finland) fitted with a De Nouy platinum ring. Conductivity measurements were performed using a Crison Conductimeter Basic 30 Crison, Barcelona, Spain) and $\mathrm{pH}$ measurements were made using a WTW Microprocessor $535 \mathrm{pH}$ meter (Los Angeles, California, USA); viscosity measurements were made using a Viscostar plus+ H (Fungilab, Barcelona, Spain) viscometer. The above properties were measured at room temperature and atmospheric pressure for 1, 7, 14, 22, 45, 60 days.

\subsubsection{Digital Printing}

Digital printing was performed on as above described pretreated cotton samples using an Epson Stylus SX218 ink-jet printer.

\section{ReSUlts AND DiscusSiON}

\subsection{Synthesis of Dyes RR(a-c)}

The reactive dyes (Figure 1) were synthesized successfully with a one-stage method as described in the experimental part and in previous work [15]. The synthesis required diazotization of 4-amino-2, 5dimethoxy phenylene-beta hydroxyl ethyl sulphone sulfate ester and coupling of the diazo compound with 1-amino-8-hydroxynaphthalene-3,6-disulphonic acid. The products derived from the coupling reactions of the two amines (Figure 1) with a molar ratio 1:1 are new monoazo reactive red dyes. The synthesis is in accordance with previous experimental data [15] while previous work [6] containing coupling of the amines with a molar ratio 1:2 resulted in disazo reactive blue dyes.

Table 1 shows the melting points, the spectrophotometrical data UV-Vis and FT-IR and the elemental analysis of the dyes.

Table1. Yield, Melting Points, Spectrophotometrical Data and Elemental Analysis for the Dyes RR(a-c) and UF $R R(a-c)$ (ultrafiltrated RRa-c)

\begin{tabular}{|c|c|c|c|c|c|c|}
\hline Dye & $\begin{array}{l}\text { Coupler(moles) } \\
\text { H-acid }\end{array}$ & $\begin{array}{l}\text { Melting } \\
\text { point }\end{array}$ & $\begin{array}{l}\text { UV-Vis } \\
\lambda \mathbf{m a x} \\
(\mathbf{n m})\end{array}$ & FT-IR & $\begin{array}{l}\text { Elemental } \\
\text { Analysis }\end{array}$ & $\begin{array}{l}\text { Yield } \\
\text { (g/moles amines) }\end{array}$ \\
\hline$\overline{\mathrm{RRa}}$ & $0.05(15.96 \mathrm{gr})$ & $270{ }^{\circ} \mathrm{C}$ & 543 & $\begin{array}{l}\mathrm{N}=\mathrm{N}-: 1488\left(\mathrm{~cm}^{-1}\right) \\
-\mathrm{C}=\mathrm{C}-: 1614\left(\mathrm{~cm}^{-1}\right) \\
\mathrm{OH}: 3435\left(\mathrm{~cm}^{-1}\right) \\
\mathrm{R}^{-} \mathrm{SO}_{3}^{-}: 1126\left(\mathrm{~cm}^{-1}\right) \\
\mathrm{R}^{-} \mathrm{SO}_{2}-\mathrm{R}: 1045\left(\mathrm{~cm}^{-1}\right)\end{array}$ & & $742.6 \mathrm{~g}$ \\
\hline $\begin{array}{l}\text { UF } \\
\text { RRa }\end{array}$ & & $270{ }^{\circ} \mathrm{C}$ & 619 & & $\begin{array}{l}\text { Found } \\
\text { C: } 29.77 \% \\
\text { H:2.98\% } \\
\text { N:4.44\% } \\
\text { Calculated } \\
\text { C:32.55\% } \\
\text { H: } 2.17 \% \\
\text { N: } 6.33 \%\end{array}$ & \\
\hline$\overline{\mathrm{RRb}}$ & $0.05(15.96 \mathrm{gr})$ & $230{ }^{\circ} \mathrm{C}$ & 548.5 & $\begin{array}{l}\mathrm{N}=\mathrm{N}-: 1504\left(\mathrm{~cm}^{-1}\right) \\
-\mathrm{C}=\mathrm{C}-: 1610\left(\mathrm{~cm}^{-1}\right) \\
\mathrm{OH}: 3443\left(\mathrm{~cm}^{-1}\right) \\
\mathrm{R}-\mathrm{SO}_{3}^{-}: 1125\left(\mathrm{~cm}^{-1}\right) \\
\mathrm{R}-\mathrm{SO}_{2}-\mathrm{R}: \quad 1043\left(\mathrm{~cm}^{-}\right. \\
1)\end{array}$ & & $779.2 \mathrm{~g}$ \\
\hline $\begin{array}{l}\mathrm{UF} \\
\mathrm{RRb}\end{array}$ & & $230{ }^{\circ} \mathrm{C}$ & 544.0 & & $\begin{array}{l}\text { Found } \\
\text { C:28.90\% }\end{array}$ & \\
\hline
\end{tabular}




\begin{tabular}{|c|c|c|c|c|c|c|}
\hline & & & & & $\begin{array}{l}\mathrm{H}: 2.67 \% \\
\mathrm{~N}: 4.21 \% \\
\text { Calculated } \\
\mathrm{C}: 30.77 \% \\
\mathrm{H}: 2.05 \% \\
\mathrm{~N}: 5.98 \%\end{array}$ & \\
\hline RRc & 0,05 (15.96gr) & $220^{\circ} \mathrm{C}$ & 545.5 & $\begin{array}{l}\mathrm{N}=\mathrm{N}-: 1488\left(\mathrm{~cm}^{-1}\right) \\
-\mathrm{C}=\mathrm{C}-: 1629\left(\mathrm{~cm}^{-1}\right) \\
\mathrm{OH}: 3672\left(\mathrm{~cm}^{-1}\right) \\
\mathrm{R}-\mathrm{SO}_{3}^{-}: 1127\left(\mathrm{~cm}^{-1}\right) \\
\mathrm{R}-\mathrm{SO}_{2}-\mathrm{R}: \quad 1051(\mathrm{~cm} \\
\left.{ }^{1}\right)\end{array}$ & & $673.2 \mathrm{~g}$ \\
\hline $\begin{array}{l}\text { UF } \\
\text { RRc }\end{array}$ & & $220^{\circ} \mathrm{C}$ & 547.0 & & $\begin{array}{l}\text { Found } \\
\text { C: } 32.64 \% \\
\text { H: } 2.27 \% \\
\text { N:5.98\% } \\
\text { Calculated } \\
\text { C: } 33.64 \% \\
\text { H: } 2.24 \% \\
\text { N: } 6.54 \%\end{array}$ & \\
\hline
\end{tabular}

From table 1 the following are concluding: The high melting points are in agreement with the melting points of dyes synthesized previously $[6,15]$ and other reactive dyes of similar structure given in the literature [19]. FT-IR analysis clearly shows the presence of main bonds formed during the synthesis of dyes and is in line with theoretical expectations [20]. In figure 3 and figures 4a,b,c representative FT-IR and the UV-vis spectra respectively are given.

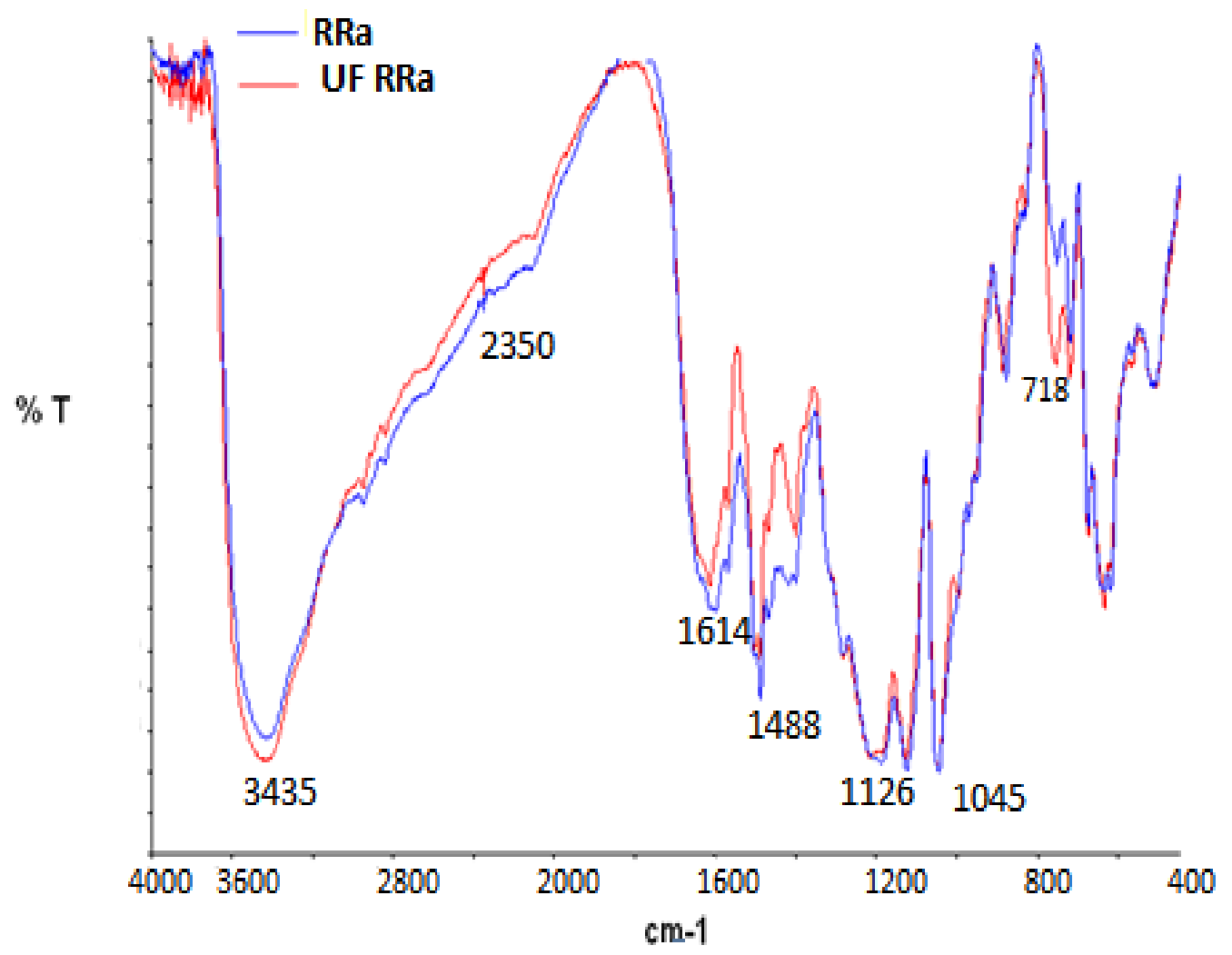

Figure3. Fourier Transform Infrared Spectra RRa and UF RRa 
Synthesis, Characterization and Ultra filtration of Reactive Dyes. Application by Exhaustion and/or InkJet Printing. III

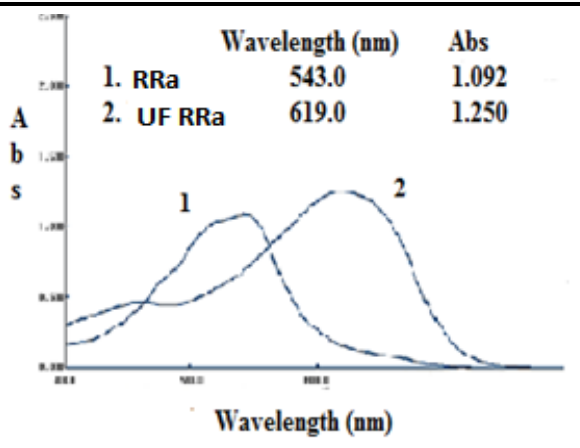

(a)

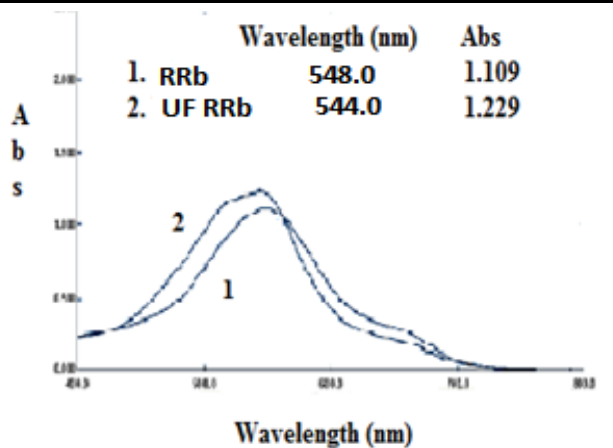

(b)

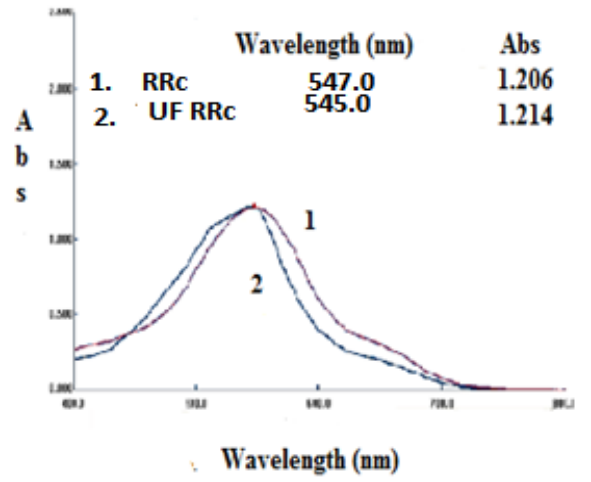

(c)

Figure. 4(a) UV-Vis RRa and UFRRa, (b) UV-Vis RRb and UF RRb, (c) UV-Vis RRc and UF RRc

\subsection{Ultrafiltration}

The synthesized dyes RR(a-c) were passed through the ultrafiltration unit housed with a PCI tubular AFC 40 polyamide membrane. The AFC 40 membrane is anisotropic with asymmetric pores. Anisotrope membranes present a thin film that avoids the entrapment of suspended solids into the membrane body and are therefore less subject to aging, clogging and fouling and flow rate reduction than symmetric membranes [21]. It is a molecular separation technique which does not require the use of chemicals but forces the molecules of certain molecular weight to pass or not through the membrane. Preliminary lab trials with a number of membranes tested, showed that the most suitable

membrane for the synthesized dyes RR(a-c) was the PCI polyamide type membrane AFC 40 in terms of inorganic salt separation and dye purification as it was concluded in previous works $[6,15]$.

Spectrophotometrical data and elemental analysis for the ultrafiltrated dyes UF RR(a-c) are given in table 1.

\subsection{Solubility of Dyes RR(a-c) and UF RR(a-c)}

Ultrafiltration also results in a significant improvement of the dye solubility. The much purer dyes resulted after ultrafiltration show much higher solubility allowing the potential use of synthesized dyes in the production of high stable high colouristic value ink jet formulations. The highest solubility increase has been observed with the K salt dye RRb followed by the Li salt dye RRc and this can be explained of the smaller molecular size of these salts. It is also known that these salts are preferred to the commonly used sodium salts in the production of high strength and high stability liquid formulations (R\&D communications Yorkshire Colours). Solubility tests conducted for the dyes $\mathrm{RR}(\mathrm{a}-\mathrm{c})$ and UF RR(a-c) confirmed the above results (Table 2).

Table2. Solubility of the Synthesized Reactive Dyes before and after ultra filtration

\begin{tabular}{|c|c|}
\hline & Solubility at $\mathbf{9 5 / 2 5} \mathbf{~}^{\mathbf{C}} \mathbf{g} \mathbf{g} \mathbf{L}$ \\
\hline RRa & 150 \\
\hline UF RRa & 260 \\
\hline RRb & 130 \\
\hline UF RRb & 250 \\
\hline RRc & 180 \\
\hline UF RRc & 320 \\
\hline
\end{tabular}




\subsection{Dyeing Strength of Dyes RR(a-c) and UF RR(a-c)}

In Table 3 the \% spectrophotometric dye strength increase after ultrafiltration is given. The elimination of all inorganic impurities results in the production of purer dyes as can be seen from the dye strength increase of the dyes after the ultrafiltration process which is of the order of ca. 10-15\% calculated from the absorbance at the corresponding $\lambda \max$ of the dyes before and after ultrafiltration. Dye strength increase did not observed for the Li salt dye (Table 3).

The dye strength increase (Figure 3a-c, Table 3) coupled with the dye solubility increase clearly shows that the ultrafiltration has dramatically improved the quality of the dyes. The dye quality improvement resulted by this membrane technology opens new areas of application of the ultra filtrated dyes such as in inkjet digital printing where dye purity and solution stability is of paramount importance.

Table3. UV-Vis Absorption before/after ultra filtration

\begin{tabular}{|c|c|c|}
\hline Dye & Abs. & \% Dye strength Increase \\
\hline RRa & 1.092 & $\mathbf{1 4 . 4 \%}$ \\
\hline UF RRa & 1.250 & $\mathbf{1 0 . 8 \%}$ \\
\hline RRb & 1.109 & \\
\hline UF RRb & 1.250 & \\
\hline RRc & 1.214 & \\
\hline UF RRc & 1.206 & \\
\hline
\end{tabular}

\subsection{Elimination of Inorganic Salts}

Table 4 clearly shows the efficiency of the selected membrane, AFC 40, in removing inorganic salts from the dye allowing the production of highly purified dyes which are suitable for the manufacturing of specialised stable digital printing inks. The removal of salts and other impurities present from the synthesis or the raw materials used increases the aqueous solubility of the dyes allowing the production of aqueous ink jet inks of high colouristic strength and of high liquid stability, properties extremely important for digital printing application

Table4. Ion Content in the Permeate Solution of the Dyes RRa-c

\begin{tabular}{|c|c|c|c|c|}
\hline & $\mathbf{N a}^{+}$ & $\mathbf{K}^{+}$ & $\mathbf{C l}^{-}$ & $\mathbf{L i}^{+}$ \\
\hline $\mathrm{RRa}$ & $30,225 \mathrm{mg} / \mathrm{Kg}$ dye & & $49,500 \mathrm{mg} / \mathrm{Kg}$ dye & \\
\hline $\mathrm{RRb}$ & $12,975 \mathrm{mg} / \mathrm{Kg}$ dye & $50,625 \mathrm{mg} / \mathrm{Kg}$ dye & $80,250 \mathrm{mg} / \mathrm{Kg}$ dye & \\
\hline $\mathrm{RRC}$ & $11,100 \mathrm{mg} / \mathrm{Kg}$ dye & & $39,975 \mathrm{mg} / \mathrm{Kg}$ dye & $3,720 \mathrm{mg} / \mathrm{Kg}$ dye \\
\hline
\end{tabular}

Table 5 shows the $\%$ rejection of inorganic $\mathrm{Na}^{+}, \mathrm{K}^{+}$and $\mathrm{Cl}^{-}$ions present in retentate dye solution and the permeate solution at the end of ultrafiltration cycle.

Table5. $\mathrm{R} \%$ (\% rejection) of Inorganic $\mathrm{Na}^{+}, \mathrm{K}^{+}, \mathrm{SO}_{4}^{-}$and $\mathrm{Cl}$ Ions Present in the Dyes $\mathrm{RR}(\mathrm{a}-\mathrm{c})$ Achieved by ultrafiltration

\begin{tabular}{|c|c|c|c|c|c|c|}
\hline & $\begin{array}{c}\mathbf{N a}^{+}, \mathbf{c}_{\mathbf{r}} \\
\text { retentate } \mathbf{c}_{\mathbf{r}}\end{array}$ & $\begin{array}{c}\mathbf{N a}^{+}, \mathbf{c}_{\mathbf{p}} \\
\text { permeate }\end{array}$ & $\begin{array}{c}\text { Rejection } \\
(\boldsymbol{\%})\end{array}$ & $\begin{array}{c}\mathbf{K}^{+} \mathbf{c}_{\mathbf{r}} \\
\text { retentate }\end{array}$ & $\begin{array}{c}\mathbf{K}^{+}, \mathbf{c}_{\mathbf{p}} \\
\text { permeate }\end{array}$ & $\mathbf{R}(\%)$ \\
\hline $\mathrm{Rra}$ & $37,080 \mathrm{mg} / \mathrm{l}$ & $362.7 \mathrm{mg} / \mathrm{l}$ & 99.00 & & & \\
\hline $\mathrm{RRb}$ & & & & $32,400 \mathrm{mg} / \mathrm{l}$ & $607.5 \mathrm{mg} / \mathrm{l}$ & 98.10 \\
\hline $\mathrm{RRc}$ & $33,000 \mathrm{mg} / \mathrm{l}$ & $133.2 \mathrm{mg} / \mathrm{l}$ & 99.60 & & & \\
\hline
\end{tabular}

High levels of electrolyte rejection in the permeate of the order $98-99.6 \%$ were achieved. The significant rejection in free metal achieved for the dyes can be attributed to the efficiency of the membrane to allow the permeation of the free metal ions through the membrane and thus achieving a cleaner dye in terms of free metal content in the final dye after ultrafiltration. Similar results were obtained in previous works $[6,15]$.

The removal efficiency of the membrane is generally expressed by the \% rejection (R) defined by Eq. (2) $[11,21-23]$.

$$
R(\%)=\left(1-\frac{c_{p}}{c_{r}}\right) \times 100
$$

where $c_{p}$ is the concentration of the permeate

$c_{r}$ is the concentration of retentate 
Synthesis, Characterization and Ultra filtration of Reactive Dyes. Application by Exhaustion and/or InkJet Printing. III

Table 5 clearly demonstrates the effectiveness of the ultrafiltration system employed to drastically eliminate the free metal, together with the inorganic ions present in the dyes.

\subsection{Dyeing}

Aqueous solutions of the synthesized dyes $R R(a-c)$ and UF RR(a-c) were used for the dyeing of cotton, wool and nylon 6,6 fibres (Fig.2a-b). The colorimetric values of the dyed samples are given in Tables 6,7 and 8 respectively.

Table6. Colorimetric Data $L^{*}, a^{*}, b^{*}, C^{*}, h^{o}$ and $K / S$ Values of the Cotton Samples Dyed $\left(60^{\circ} C\right)$ with the Dyes $R R(a-c)$ and $U F R R(a-c)$

\begin{tabular}{|c|c|c|c|c|c|c|c|}
\hline Dye & $\mathbf{K} / \mathbf{S}$ & $\boldsymbol{\lambda} \mathbf{m a x}(\mathbf{n m})$ & $\mathbf{L}^{*}$ & $\mathbf{a}^{*}$ & $\mathbf{b}^{*}$ & $\mathbf{C}^{*}$ & $\mathbf{h}^{\mathbf{*}}$ \\
\hline RRa & 11.45 & 580 & 33.55 & 9.96 & -28.18 & 29.89 & 289.47 \\
\hline UF RRa & 13.85 & 560 & 29.24 & 10.54 & -26.17 & 28.21 & 291.94 \\
\hline RRb & 11.87 & 570 & 26.72 & 8.34 & -23.28 & 24.73 & 289.71 \\
\hline UF RRb & 16.26 & 570 & 22.85 & 8.29 & -25.25 & 26.57 & 288.17 \\
\hline RRc & 11.13 & 580 & 27.66 & 8.77 & -26.66 & 28.07 & 288.22 \\
\hline UF RRc & 12.21 & 570 & 27.73 & 8.77 & -21.59 & 23.30 & 292.11 \\
\hline
\end{tabular}

Table7. Colorimetric Data $L^{*}, a^{*}, b^{*}, C^{*}, h^{o}$ and $K / S$ Values of the Wool Samples Dyed $\left(60^{\circ} C\right)$ with the Dyes $R R(a-c)$ and $U F R R(a-c)$

\begin{tabular}{|c|c|c|c|c|c|c|c|}
\hline Dye & $\mathbf{K} / \mathbf{S}$ & $\boldsymbol{\lambda} \mathbf{m a x}(\mathbf{n m})$ & $\mathbf{L}^{*}$ & $\mathbf{a}^{*}$ & $\mathbf{b}^{*}$ & $\mathbf{C}^{*}$ & $\mathbf{h}^{\mathbf{*}}$ \\
\hline $\mathrm{RRa}$ & 20.11 & 550 & 21.17 & 14.24 & -14.01 & 19.98 & 315.46 \\
\hline UF RRa & 21.39 & 550 & 22.76 & 15.74 & -20.96 & 26.21 & 306.91 \\
\hline RRb & 18.47 & 550 & 22.13 & 13.56 & -20.56 & 24.63 & 303.40 \\
\hline UF RRb & 24.52 & 560 & 18.16 & 9.68 & -15.31 & 18.12 & 302.31 \\
\hline RRc & 23.16 & 550 & 19.57 & 13.46 & -15.69 & 20.67 & 310.62 \\
\hline UF RRc & 16.87 & 550 & 23.24 & 13.78 & -21.03 & 25.15 & 303.23 \\
\hline
\end{tabular}

Table8. Colorimetric Data $L^{*}, a^{*}, b^{*}, C^{*}, h^{o}$ and K/S Values of the Nylon 6,6 Samples Dyed $\left(60^{\circ} C\right)$ with the Dyes $R R(a-c)$ and $U F R R(a-c)$

\begin{tabular}{|c|c|c|c|c|c|c|c|}
\hline Dye & $\mathbf{K} / \mathbf{S}$ & $\boldsymbol{\lambda} \mathbf{m a x}(\mathbf{n m})$ & $\mathbf{L}^{*}$ & $\mathbf{a}^{*}$ & $\mathbf{b}^{*}$ & $\mathbf{C}^{*}$ & $\mathbf{h}^{\mathbf{*}}$ \\
\hline RRa & 10.90 & 550 & 33.26 & 24.72 & -20.03 & 31.82 & 320.99 \\
\hline UF RRa & 11.68 & 550 & 32.27 & 24.49 & -19.88 & 31.54 & 320.93 \\
\hline RRb & 10.06 & 560 & 30.59 & 14.85 & -22.22 & 26.72 & 303.75 \\
\hline UF RRb & 10.68 & 550 & 31.09 & 19.32 & -22.88 & 29.95 & 310.10 \\
\hline RRc & 10.76 & 550 & 30.91 & 19.12 & -23.24 & 30.09 & 309.45 \\
\hline UF RRc & 11.35 & 550 & 29.55 & 19.79 & -22.41 & 29.89 & 311.45 \\
\hline
\end{tabular}

The K/S values of the dyed samples with ultrafiltrated dyes are higher than the corresponding K/S values obtained with non ultrafiltrated dyed samples. This is in agreement with previous findings (Table 3) shown the \% dye strength increase measured from the dye solutions before and after ultrafiltration and can be explained in same terms as above with the removal of inorganic salts and other impurities in the permeate solution (Table 5) $[15,19]$. The other colouristic co-ordinates such as $L^{*}, a^{*}, b^{*}, C^{*}, h^{o}$ values are in line with strength changes not showing significant colour changes before and after ultrafiltration.

In Tables 9-11 the wash and light fastness properties of the cotton, wool and nylon 66 samples respectively dyed with the dyes $\mathrm{RR}(\mathrm{a}-\mathrm{c})$ and UF $\mathrm{RR}(\mathrm{a}-\mathrm{c})$ are given.

Table9. Wash and light Fastness of Cotton Samples Dyed $\left(60^{\circ} \mathrm{C}\right)$ with the Dyes $R R(a-c)$ and UF RR(a-c)

\begin{tabular}{|c|c|c|c|c|}
\hline Dye & & Wash Fastness & Light Fastness \\
\hline & ${ }^{\mathrm{a}} \mathbf{C C}$ & ${ }^{\mathbf{b}} \mathbf{C S}$ & \\
\hline RRa & 4 & $\mathrm{diac}=5, \mathrm{c}=5, \mathrm{pa}=5, \mathrm{pes}=5, \mathrm{pac}=5, \mathrm{w}=5$ & 4 \\
\hline UF RRa & 5 & $\mathrm{diac}=5, \mathrm{c}=5, \mathrm{pa}=5, \mathrm{pes}=5, \mathrm{pac}=5, \mathrm{w}=5$ & 4 \\
\hline $\mathrm{RRb}$ & 5 & $\mathrm{diac}=5, \mathrm{c}=5, \mathrm{pa}=5, \mathrm{pes}=5, \mathrm{pac}=5, \mathrm{w}=5$ & $4-5$ \\
\hline UF RRb & 5 & $\mathrm{diac}=5, \mathrm{c}=5, \mathrm{pa}=5, \mathrm{pes}=5, \mathrm{pac}=5, \mathrm{w}=5$ & $4-5$ \\
\hline RRc & 4 & $\mathrm{diac}=5, \mathrm{c}=5, \mathrm{pa}=5, \mathrm{pes}=5, \mathrm{pac}=5, \mathrm{w}=5$ & $4-5$ \\
\hline UF RRc & 5 & diac=5, $\mathrm{c}=5, \mathrm{pa}=5, \mathrm{pes}=5, \mathrm{pac}=5, \mathrm{w}=5$ & \\
\hline
\end{tabular}

${ }^{a} \mathrm{CC}=$ colour change

${ }^{b}$ CS =colour staining: diac $=$ diacetate,$c=$ cotton, $p a=$ polyamide, $p e s=$ polyester,$w=$ wool 
Smaro Lykidou et al.

Table10. Wash and Light Fastness of Wool Samples Dyed $\left(60^{\circ} \mathrm{C}\right)$ with the dyes RR(a-c) and UF RR(a-c)

\begin{tabular}{|c|c|c|c|c|}
\hline Dye & & Wash Fastness & & $\begin{array}{c}\text { Light } \\
\text { Fastness }\end{array}$ \\
\hline & ${ }^{\mathrm{a}} \mathbf{C C}$ & ${ }^{\mathrm{b}} \mathrm{CS}$ & & \\
\hline $\mathrm{RRa}$ & 4 & \multicolumn{2}{|c|}{$\operatorname{diac}=5, \mathrm{c}=4 / 5, \mathrm{pa}=5, \mathrm{pes}=5, \mathrm{pac}=5, \mathrm{w}=5$} & 4 \\
\hline UF RRa & 4 & \multicolumn{2}{|c|}{$\operatorname{diac}=5, \mathrm{c}=4, \mathrm{pa}=5, \mathrm{pes}=5, \mathrm{pac}=5, \mathrm{w}=5$} & $3-4$ \\
\hline $\mathrm{RRb}$ & $4 / 5$ & \multicolumn{2}{|c|}{$\operatorname{diac}=5, \mathrm{c}=4, \mathrm{pa}=5, \mathrm{pes}=5, \mathrm{pac}=5, \mathrm{w}=5$} & 5 \\
\hline $\mathrm{UF} \mathrm{RRb}$ & 4 & \multicolumn{2}{|c|}{$\operatorname{diac}=5, \mathrm{c}=4 / 5, \mathrm{pa}=5, \mathrm{pes}=5, \mathrm{pac}=5, \mathrm{w}=5$} & $3-4$ \\
\hline RRc & 4 & \multicolumn{2}{|c|}{$\operatorname{diac}=5, \mathrm{c}=4 / 5, \mathrm{pa}=5, \mathrm{pes}=5, \mathrm{pac}=5, \mathrm{w}=5$} & 5 \\
\hline UF RRc & $4 / 5$ & \multicolumn{2}{|c|}{$\operatorname{diac}=5, \mathrm{c}=4, \mathrm{pa}=5, \mathrm{pes}=5, \mathrm{pac}=5, \mathrm{w}=5$} & 4 \\
\hline
\end{tabular}

${ }^{a, b}$ As in table 9

Table11. Wash and Light Fastness of Nylon 66 Samples Dyed $\left(60^{\circ} \mathrm{C}\right)$ with the Dyes RR(a-c) and UF RR(a-c)

\begin{tabular}{|c|c|c|c|}
\hline Dye & & Wash Fastness & $\begin{array}{c}\text { Light } \\
\text { Fastness }\end{array}$ \\
\hline & ${ }^{\mathrm{a}} \mathbf{C C}$ & ${ }^{\mathbf{b}} \mathrm{CS}$ & \\
\hline $\mathrm{RRa}$ & $4 / 5$ & $\operatorname{diac}=5, \mathrm{c}=5, \mathrm{pa}=5, \mathrm{pes}=5, \mathrm{pac}=5, \mathrm{w}=5$ & 4 \\
\hline UF RRa & $4 / 5$ & $\operatorname{diac}=5, \mathrm{c}=5, \mathrm{pa}=5, \mathrm{pes}=5, \mathrm{pac}=5, \mathrm{w}=5$ & $3-4$ \\
\hline $\mathrm{RRb}$ & 5 & $\operatorname{diac}=5, c=5, p a=5, p e s=5, p a c=5, w=5$ & $3-4$ \\
\hline UF RRb & $4 / 5$ & $\operatorname{diac}=5, \mathrm{c}=5, \mathrm{pa}=5, \mathrm{pes}=5, \mathrm{pac}=5, \mathrm{w}=5$ & $3-4$ \\
\hline RRc & $4 / 5$ & $\operatorname{diac}=5, \mathrm{c}=5, \mathrm{pa}=5, \mathrm{pes}=5, \mathrm{pac}=5, \mathrm{w}=5$ & $2-3$ \\
\hline UF RRc & $4 / 5$ & $\operatorname{diac}=5, \mathrm{c}=5, \mathrm{pa}=5, \mathrm{pes}=5, \mathrm{pac}=5, \mathrm{w}=5$ & $2-3$ \\
\hline
\end{tabular}

${ }^{a, b}$ As in table 9

The dyes RR(a-c) have very good to excellent wash fastness in all cases as should have been expected for reactive dyes. Light fastness values are medium to low. Ultrafiltration slightly improves the light fastness properties which can be attributed to the elimination of by-products which affect fastness to light. Similar results were obtained previously $[6,15]$.

\subsection{Ink-jet Printing}

Ink-jet ink formulations were prepared using the ultrafiltrated dyes UF RR(a-c). The ultrafiltrated dyes with increased colouristic yield coupled with higher solubility are extremely suitable for the production of high quality digital printing inks avoiding nozzle damages and blockages.

\subsection{Measurement of Inkjet Inks Properties}

Monitoring a digital ink formulation over a period of time is a widely accepted method for evaluating stability of the inkjet ink $[12,13]$. In this study the $\mathrm{pH}$, conductivity, surface tension and viscosity of the inkjet ink formulations prepared with the ultrafiltrated dyes were monitored over a period of 90 days.

In Figure 5 the plots of the $\mathrm{pH}$ values against time are given for the dyes RRa and UF RRa. The $\mathrm{pH}$ stability of the inkjet inks remains relatively stable over the period of 90 days which is a good indication regarding the suitability of the inks for digital printing application. According to the literature commercial inkjet ink formulations should have $\mathrm{pH}$ values in acid or near the neutral region [12-14]. The present $\mathrm{pH}$ values range within acceptable limits.

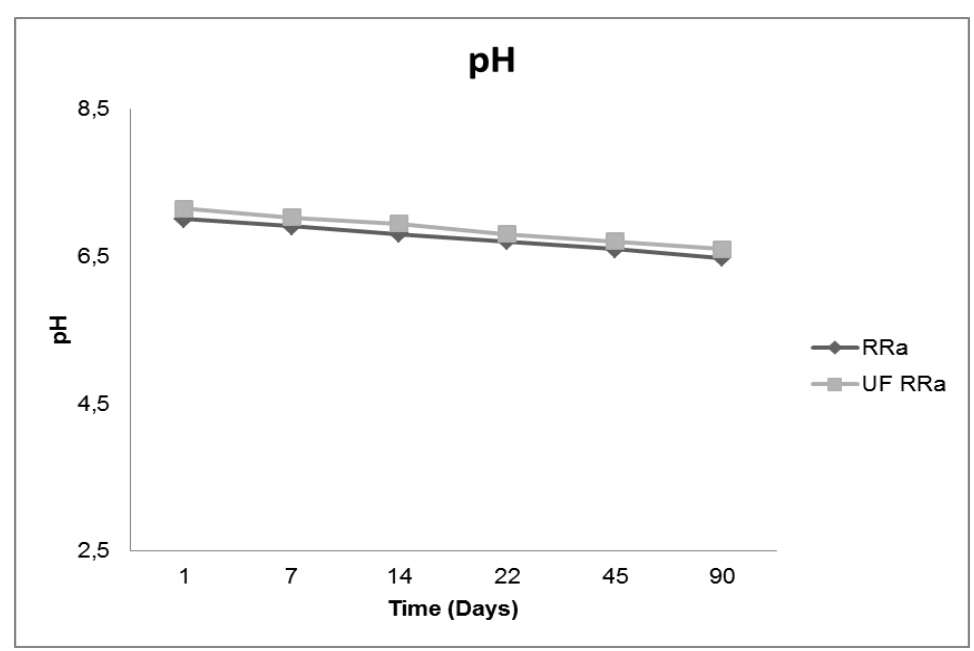

Figure5. $p H$ Values vs time for the Dyes RRa and UF RRa Ink Formulations 
Figure 6 shows the conductivity values of the digital printing inks RRa and UF RRa over a period of 90 days time. Inkjet inks show high conductivity values which can be attributed to the presence of three ionizable sulphonic acid groups present in the dye molecules.

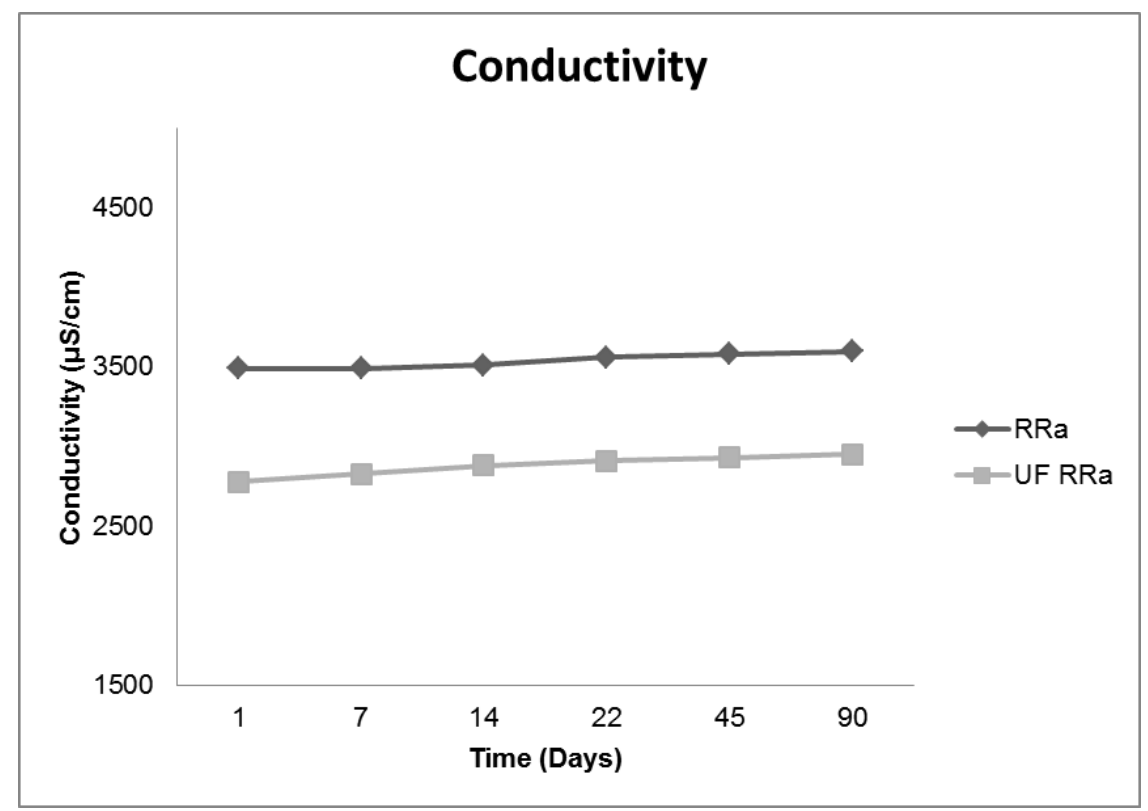

Figure6. Plots of Conductivity Values vs time for the Dyes UF RR (a-c) Ink Formulations

Conductivity values of all inks remain stable over the period of 90 days which is a good sign regarding the inks stability and suitability for digital printing application. Ultrafiltration results in significant conductivity lowering due to the elimination of inorganic salts either present in the raw materials or added during the synthesis process (Table 5).

Acceptable viscosity values for ink-jet ink formulations are said to be between 2.2-3.4cp [14] for digital printing application, although it is not unknown for such inks to have a viscosity up to $3-5 \mathrm{cp}$ $[14,24]$. Viscosity values of the inks UFRRa are increasing slowly but remain within these limits over a period of 18 days and become unacceptably high afterwards (figure 8). Viscosity values of the ultrafiltrated dye UF RRa are slightly lower than the values of RRa.

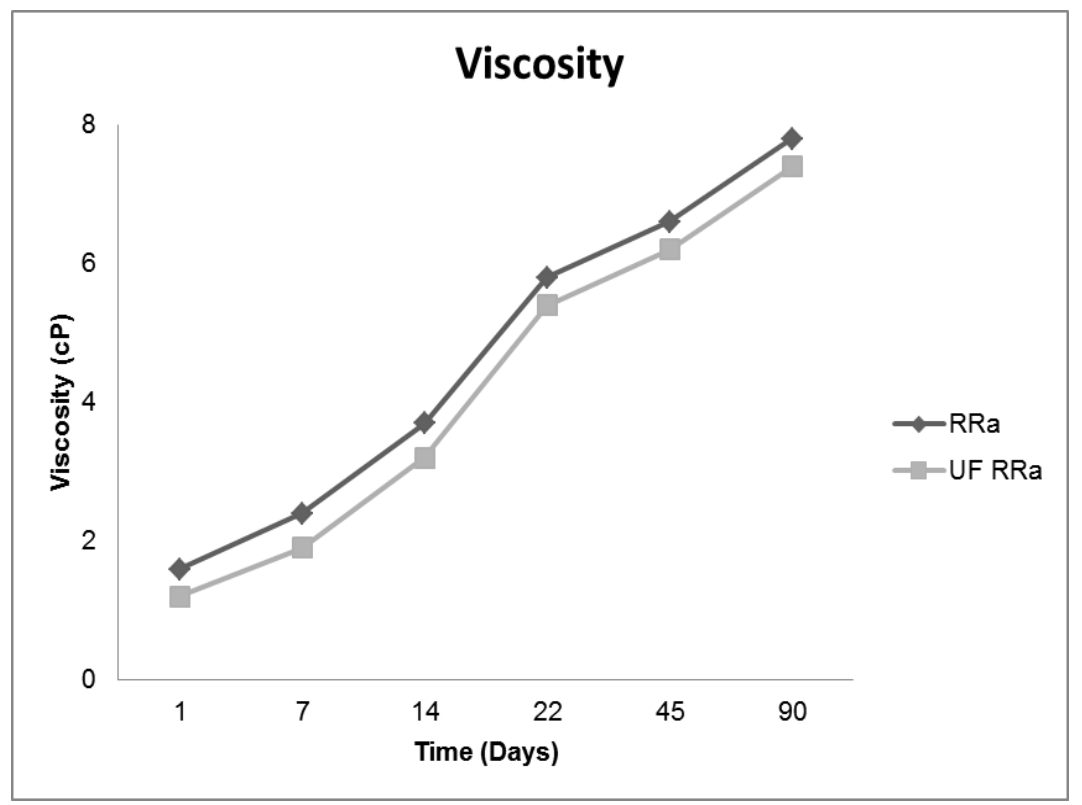

Figure8. Plots of Viscosity Values vs time for the Dyes UF RR(a-c) Ink Formulations

Surface tension values of commercial ink-jet inks for textile printing are in range 21-48 or 30-60 $\mathrm{mNm}^{-1}$ [14]. As figure 9 shows the surface tension values of the inks are of this range remain relatively stable over 90 days. 


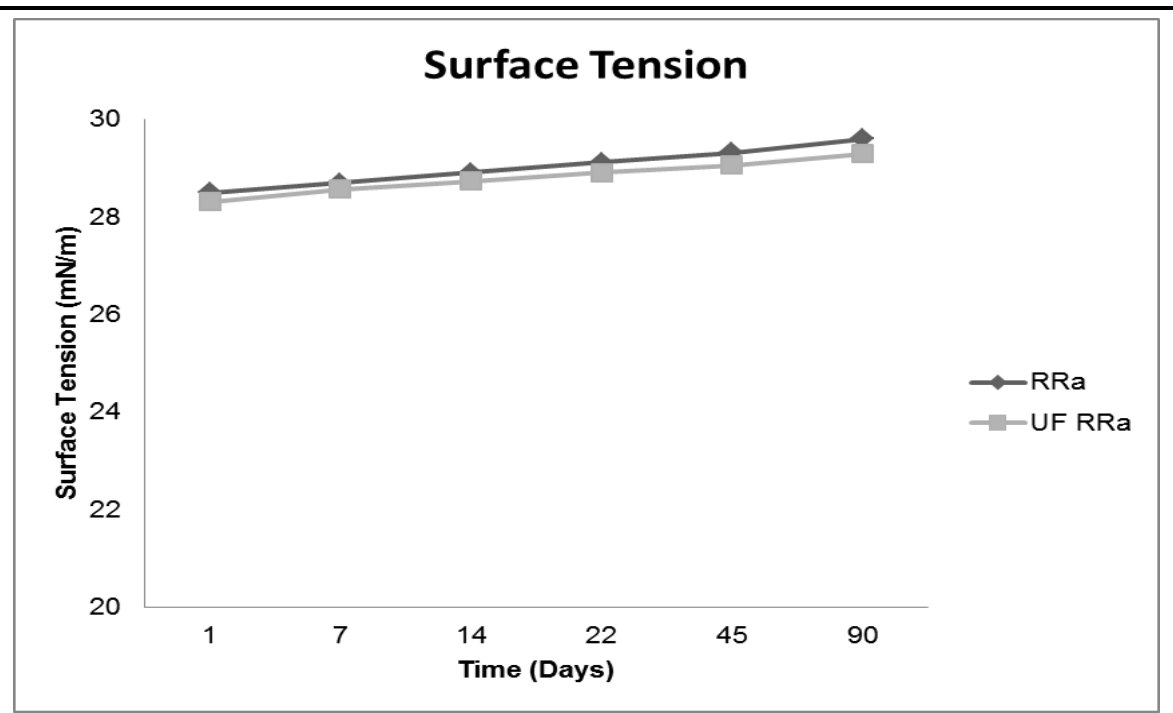

Figure9. Plots of Surface Tension Values vs time for the Dyes UF RR(a-c) Ink Formulations

\subsection{Textile Printing}

The inks prepared were used to print cotton and nylon 66 samples which were pretreated as described above. In Tables 12, 13 colorimetric data $\mathrm{L}^{*}, \mathrm{a}^{*}, \mathrm{~b}^{*}, \mathrm{C}^{*}, \mathrm{~h}^{\circ}$ and $\mathrm{K} / \mathrm{S}$ values of the nylon 66 and cotton prints respectively are given.

Table12. Colorimetric Data $L^{*}, a^{*}, b^{*}, C^{*}, h^{o}$ and K/S Values of the Cotton Prints

\begin{tabular}{|c|c|c|c|c|c|c|c|}
\hline Dye & $\mathbf{K} / \mathbf{S}$ & $\mathbf{\lambda m a x}$ & $\mathbf{L}^{*}$ & $\mathbf{a}^{*}$ & $\mathbf{b}^{*}$ & $\mathbf{C}^{*}$ & $\mathbf{h}^{\mathbf{0}}$ \\
\hline $\mathrm{RRa}$ & 0.0846 & 400 & 64.81 & 6.06 & -2.27 & 6.48 & 339.45 \\
\hline UF RRa & 0.6471 & 400 & 73.86 & 4.71 & 6.47 & 8.00 & 53.96 \\
\hline
\end{tabular}

Table13. Colorimetric Data $L^{*}, a^{*}, b^{*}, C^{*}, h^{o}$ and $K / S$ Values of the Nylon 6,6 Prints

\begin{tabular}{|c|c|c|c|c|c|c|c|}
\hline Dye & K/S & $\mathbf{\lambda} \mathbf{m a x}$ & $\mathbf{L}^{*}$ & $\mathbf{a}^{*}$ & $\mathbf{b}^{*}$ & $\mathbf{C}^{*}$ & $\mathbf{h}^{\mathbf{0}}$ \\
\hline $\mathrm{RRa}$ & 0.0631 & 400 & 91.11 & 1.05 & 1.81 & 2.09 & 59.87 \\
\hline UF RRa & 0.067 & 400 & 88.54 & 3.10 & -0.22 & 3.11 & 355.93 \\
\hline
\end{tabular}

Wash fastness properties of the cotton and nylon 66 prints are excellent while light fastness values are low. Slight light fastness improvement is achieved by ultrafiltration.

Table14. Wash and Light Fastness of Nylon 6,6 Printed with the Dyes RRa and UF RRa

\begin{tabular}{|c|c|c|l|c|}
\hline Dye & & Wash Fastness & Light Fastness \\
\hline & ${ }^{\mathbf{a}} \mathbf{C C}$ & ${ }^{\mathbf{b}} \mathbf{C S}$ & & \\
\hline $\mathrm{RRa}$ & 5 & $\mathrm{diac}=5, \mathrm{c}=5, \mathrm{pa}=5, \mathrm{pes}=5, \mathrm{pac}=5, \mathrm{w}=5$ & $2-3$ \\
\hline UF RRa & 5 & $\mathrm{diac}=5, \mathrm{c}=5, \mathrm{pa}=5, \mathrm{pes}=5, \mathrm{pac}=5, \mathrm{w}=5$ & 3 \\
\hline
\end{tabular}

${ }^{a} \mathrm{CC}=$ colour change

${ }^{b} C S=$ colour staining: diac $=$ diacetate,$c=$ cotton, $p a=$ polyamide, $p e s=$ polyester,$w=$ wool

Table15. Wash and Light Fastness of Cotton Printed with the Dyes RRa and UF RRa

\begin{tabular}{|c|c|c|l|c|}
\hline Dye & & Wash Fastness & Light Fastness \\
\hline RRa & ${ }^{\mathbf{a}} \mathbf{C C}$ & ${ }^{\mathbf{b}} \mathbf{C S}$ & \\
\hline UF RRa & 5 & $\mathrm{diac}=5, \mathrm{c}=5, \mathrm{pa}=5, \mathrm{pes}=5, \mathrm{pac}=5, \mathrm{w}=5$ & $2-3$ \\
\hline${ }^{a, b}$ As in table 14 & 5 & $\mathrm{diac}=5, \mathrm{c}=5, \mathrm{pa}=5, \mathrm{pes}=5, \mathrm{pac}=5, \mathrm{w}=5$ & 3 \\
\hline
\end{tabular}

\section{CONCLuSion}

Three novel azo monofunctional vinyl sulphone reactive dyes have been synthesized. The synthesized dyes were ultra filtrated using AFC 40 polyamide type membranes. The dyes were characterized by their spectrophotometrical data UV-Vis and FT-IR, Optical Emission Spectroscopy and their elemental analysis. The ultrafiltration resulted in the production of high solubility and purer dyes as can be seen from the dye strength increase of the dyes after the ultrafiltration process and the elimination of inorganic salts resent in the dye after synthesis. Ultrafiltrated digital ink jet printing 
inks were prepared and their properties such as $\mathrm{pH}$, conductivity, surface tension, viscosity were monitored over a period of time. The ultrafiltrated and the non ultra filtrated counter parts were used to dye and digitally print cotton, wool and polyamide samples. Colour measurements and quality fastness tests were performed for the dyed and printed samples. These exhibited high levels of washing fastness and medium to low light fastness. The implementation of ultra filtration process in the synthesis of the three reactive dyes allowed the production of purer dyes with increased coloristic yield and the production of stable water based digital printing inks. Ultrafiltration technology opens new areas of dye applications in the high added value of digital printing industry.

\section{REFERENCES}

[1] Patel D. R., Patel N. S., Patel H. S. and Patel K. C., Synthesis, characterization and application of novel bisazo reactive dyes on various fibers, Orbital Elec. J. Chem. 3, 57 (2001).

[2] Bulearca M., Bulearca A. and Sebe I., Synthesis of Reactive Dyes Based on Epichlorhydrine, UPB Sci. Bull. 6821 (2006).

[3] Saeed Q., Bhatti I. A., Zuber M., Nosheen S., Zia M. A. and Abbas M., Synthesis and Applications of Three Vinylsulfone Based Fiber-reactive azo Dyes for Dyeing Cotton, Int. J. Basic Appl. Sci. IJBAS-IJENS. 12(6), 129 (2012).

[4] Zarkogianni M., Coutouli-Argyropoulou E., Samara C., Anthemidis A., Nikolaidis N. and Tsatsaroni* E, .A Novel Synthesis, Characterization and Application of an Anionic Crcomplexed Azo Dye Based on Environmental Considerations, Text. Res. J. 82(20), 2061 (2012).

[5] Karanikas V., Nikolaidis N. and Tsatsaroni* E., Disperse Ink-jet Inks with Active Agents: Properties and Application to Polyester and Polyamide Fibres, Text. Res. J. 0(00), 1 (2015) DOI:10.1177/0040517512452950.

[6] Lykidou S., Karanikas E., Nikolaidis N. and Tsatsaroni E., Azo reactive dyes. Ultrafiltration and application to cotton by exhaustion and digital ink-jet printing, Text. Res. J. DOI: $10.1177 / 0040517515590415$.

[7] Maraicci M., Nosenzo G., Capanelli G., Ciabatti I., Corviery D. and Ciarelelli G., Treatment and reuse of textile effluents based on new ultra-filtration and other membrane technologies, Desalination. 13875 (2001).

[8] Ciardelli G., Corsi L. and Marcucci M., Membrane separation for wastewater reuse in the textile industry, Resour. Conser. Recy. 31(2), 189 (2001).

[9] Saffaj N., Loukilia H., Alami Younssia S., Albizanea A., Bouhriaa M., Persin M. and Larbot A., Filtration of solution containing heavy metals and dyes by means of ultra-filtration membranes deposited on support made of Moroccan clay, Desalination. 168301 (2004).

[10] Simonic M., Efficiency of ultra-filtration for the pre-treatment of dye-bath effluents, Desalination. 246328 (2009).

[11] Kim T. H., Park C. and Kim S., Water recycling from desalination and purification process of reactive dye manufacturing industry by combined membrane filtration, J. Cleaner Prod. 13(8) 779 (2005).

[12] Daplyn S. and Lin L., Evaluation of pigmented ink formulations for jet printing onto textile fabrics, Pigm. Resin Technol. 32(5) 307 (2003).

[13] Kang H.R., Water based ink jet ink. II. Characterization, J. Imaging Sci. Technol. 35(3) 189 (1991).

[14] Holme I., Digital ink jet printing of textiles. Textil. Mag. 111 (2004).

[15] Lykidou S., Karanikas E., Nikolaidis N. and Tsatsaroni E., Synthesis, characterization and ultrafiltration of reactive dyes. Application by exhaustion and/or ink-jet printing. II, Text. Res. J. accepted for publication.

[16] LST 09 Solubility Test Method Yorkshire Chemicals, 2001).

[17] Standard Methods for the Determination of the Colour Fastness of Textiles and Leather. Society of Dyers and Colourists, Bradford, UK, 1990.

[18] MacDonald R (ed.) Colour physics for industry, 2nd edn. Bradford: Society of Dyers and Colourists, 1997, p.178. 
[19] Salar, R. K., Rohilla, S. K. and Rohilla J. K., Decolorization of Reactive Black HFGR by Aspergillussulphureus, Annals of Biol. Res., 3(8) 3811 (2012).

[20] Yuen C.W.M., Ku S.K.A., Choi P.S.R, Kan C.W., and Tsang S.Y., Determining Functional Groups of Commercially Available Ink-Jet Printing Reactive Dyes Using Infrared Spectroscopy, RJTA. 9(2) 26 (2005).

[21] Sagle A. and Freeman B., Fundamentals of Membranes for Water Treatment, The Future of Desalination in Texas. 2(363) 137 (2004).

[22] He Y., Li G., Wang H., Zhao J., Su H. and Huang Q., Effect of operating conditions on separation performance of reactive dye solution with membrane process, J. Membr. Sci. 321183 (2008).

[23] Huang J. and Zhang K., The high flux poly(m-phenylene isophthalamide) nanofiltration membrane for dye purification and desalination, Desalination. 28219 (2008).

[24] Siemensmeyer K. and Dover M., Tinten fuer den digitalen Textildruck, Melliand Textil. 79867 (1993). 